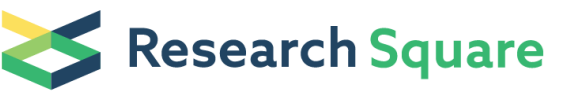 \\ Preprints are preliminary reports that have not undergone peer review. \\ They should not be considered conclusive, used to inform clinical practice, or referenced by the media as validated information.
}

\section{Nitrogen Dioxide Exposure During Pregnancy and Risk of Spontaneous Abortion: A Case-control Study in China}

\section{Beiying Wang}

Shanghai First Maternity and Infant Hospital,Tongji University School of Medicine,Shanghai 201204,P.R.China

\section{Wei Hong}

Shanghai First Maternity and Infant Hospital,Tongji University School of Medicine,Shanghai 201204.P.R.China

\section{Qingjing Sheng}

Shanghai First Maternity and Infant Hospital,Tongji University School of Medicine,Shanghai 201204,P.R. China

\section{Zhiping Wu}

Shanghai First Maternity and Infant Hospital,Tongji University School of Medicine,Shanghai 201204,P.R. China

\section{Li Li}

Tongji University School of Medicine

Xiao-Cui Li ( $\nabla$ sisi1113@163.com)

Tongji University School of Medicine https://orcid.org/0000-0003-1344-0796

\section{Research}

Keywords: Spontaneous abortion, Nitrogen dioxide, Carbon monoxide, Case-control study

Posted Date: July 15th, 2020

DOI: https://doi.org/10.21203/rs.3.rs-39405/v1

License: (c) (i) This work is licensed under a Creative Commons Attribution 4.0 International License. Read Full License 


\section{Abstract \\ Background}

Evidence on the relationship between prenatal exposure to $\mathrm{NO}_{2}$ and $\mathrm{CO}$ and spontaneous abortion (SAB) is insufficient. We investigated whether there is an association between maternal exposure to nitrogen dioxide $\left(\mathrm{NO}_{2}\right)$ and carbon monoxide $(\mathrm{CO})$ before and during pregnancy and SAB.

\section{Methods}

We conducted a case-control study using medical records of 2445 pregnant women who admitted for abortion prior to 20 weeks of gestational age from January 2014 to December 2019 at a tertiary-care hospital in Shanghai, China. Of the 2445 participants, 1075 were SAB cases and 1370 were healthy controls (underwent elective abortions). Maternal exposure to $\mathrm{NO}_{2}$ and $\mathrm{CO}$ before and during pregnancy was estimated using daily air pollution concentration data. Multivariable logistic regression models were constructed to quantify the relationships between maternal exposure to $\mathrm{NO}_{2}$ or $\mathrm{CO}$ and the risk of $\mathrm{SAB}$ while controlling for potential confounders.

\section{Results}

$\mathrm{NO}_{2}$ exposure levels during pregnancy were significantly higher in $\mathrm{SAB}$ cases than in healthy controls (42.26 vs $40.67, \mathrm{P}<0.01$ ). $\mathrm{NO}_{2}$ exposure during pregnancy was positively associated with the risk of $\mathrm{SAB}$. An interquartile range $\left(16 \mu \mathrm{g} / \mathrm{m}^{3}\right)$ increase in $\mathrm{NO}_{2}$ exposure was associated with $67 \%$ increase in the odds of $\mathrm{SAB}(\mathrm{OR}=1.67,95 \% \mathrm{Cl}, 1.28,2.18)$. Analyses of associations by quartile of $\mathrm{NO}_{2}$ exposure showed that elevated $\mathrm{NO}_{2}$ exposure during pregnancy was associated with increased odds of $\mathrm{SAB}$ in linear doseresponse manners. Compared with the lowest quartile of $\mathrm{NO}_{2}$ exposure, the odds of $\mathrm{SAB}$ in the fourth quartile of $\mathrm{NO}_{2}$ exposure increased $60 \%(\mathrm{OR}=1.60,95 \% \mathrm{Cl}, 1.03-2.49)$. No associations of $\mathrm{CO}$ exposure with SAB risk were observed.

\section{Conclusion}

Our study suggested that exposure to $\mathrm{NO}_{2}$ during early pregnancy was associated with increased risk of $S A B$. Further studies are need to confirm our results and explore the potential biological mechanism underlying these associations.

\section{Introduction}

Ambient air pollution is the most serious environmental threat and represents a major mortality risk factor worldwide [1]. According to a recent global diseases burden estimates, exposure to ambient air pollution 
from particulate matter caused about 4.2 million deaths and 103.1 million disability-adjusted life-years (DALYs) in 2015 [2].

The cardiovascular and respiratory effects of air pollution have been well documented $[3,4]$. Recently, its reproductive and developmental toxicity has raised concern. Numerous epidemiological studies have reported significant associations between prenatal exposure to air pollution and increased risk of adverse pregnancy outcomes [5]. Those adverse pregnancy outcomes included low birth weight (LBW), fetal growth restriction (FGR), preterm birth (PTB) and birth defects [6-8].

Spontaneous abortion (SAB) or miscarriage, a common and serve complication of pregnancy, defined as the spontaneous loss of a pregnancy before 20 weeks of pregnancy [9]. At least $25 \%$ of all women experience one or more sporadic miscarriages [10]. Detrimental effects of air pollution on SAB have been previously suggested with exposure to particulate matter (PM) and some gaseous pollutants [11. Most of the previous studies reported strong associations of high PM [12-15], sulfur dioxide $\left(\mathrm{SO}_{2}\right)[16,17]$ and ozone $\left(\mathrm{O}_{3}\right)[12,15,18]$ exposure with increased risk of SAB. However, evidence regarding nitrogen dioxide $\left(\mathrm{NO}_{2}\right)$ and carbon monoxide (CO) are insufficient and less inclusive, suggesting more studies are warranted to better understand their associations with SAB risk [11].

In this study, using clinal records of abortions in a tertiary hospital in Shanghai, China, we conducted a case-control study to examine whether maternal exposure to $\mathrm{NO}_{2}$ and $\mathrm{CO}$ before and during pregnancy was associated with increased risk of SAB.

\section{Methods}

\section{Study Design and Subjects}

A retrospective review of the medical records of abortions was conducted at Shanghai First Maternity and Infant Hospital, which is a tertiary-care hospital serving approximately 45,000 inpatients per year in Shanghai, China. The electronic medical record system of our hospital was used for data collection. From January 2014 to December 2019, a total of 2445 singleton pregnant women, aged between 14 to 48 years, admitted for abortion prior to 20 weeks of gestational age (GA). Of the 2445 pregnant women, 1075 were diagnosed as having missed abortion and were enrolled as SAB cases. While 1370 women with normal pregnancies who requested induced abortion due to unplanned or unwanted pregnancy were enrolled as healthy controls.

Maternal demographic characteristics including maternal age (MA), menstrual cycles, weight and height, the use of assisted reproduction technology (ART) and reproductive history were collected. GA was calculated based on the last menstrual period (LMP) of pregnant women and confirmed by ultrasound. The study protocol was approved and monitored by the medical Ethics Committee of the Shanghai First Maternity and Infant Hospital (NO. KS2008). Since all data were from medical record and used anonymously, there was no informed consent. 


\section{Air Pollution Exposure Assessment}

Daily (24-h) $\mathrm{NO}_{2}$ and $\mathrm{CO}$ concentration data for each of the 16 administrative districts in Shanghai city, from May 1, 2013 to December 30, 2019, were obtained from the database of the Shanghai Environmental Monitoring Center (SEMC). The daily concentrations of $\mathrm{NO}_{2}$ and $\mathrm{CO}$ in each district were averaged from the available data of all fixed-site monitoring stations. Ambient $\mathrm{NO}_{2}$ and $\mathrm{CO}$ measurements in each monitoring stations relied on a chemiluminescence detection method (API 200e, Thermo 42i) and a gas filter correlation method (API 300e, Thermo 48i), respectively. All ambient measurements of $\mathrm{NO}_{2}$ and $\mathrm{CO}$ were operated under the China National Quality Control Automated methods [(GB3095-2012) and (HJ/T 193-2005)] for ambient air quality monitoring. In order to adjust for the potential confounding effects of weather on SAB, we also obtained daily 24-h mean temperature and relative humidity from the database of the Shanghai Meteorological Bureau.

To explore the critical exposure time windows of $\mathrm{NO}_{2}$ and $\mathrm{CO}$ on $\mathrm{SAB}$, we examined four exposure time windows for each subject (Phases 1-4). The four exposure windows were defined as follows: Phase 1 , from the first day of LMP to the date of abortion; Phase 2, 30 days before the first day of the LMP; Phase 3,60 days before the first day of the LMP; Phase 4, 90 days before the first day of the LMP. The phaseaveraged values of daily concentrations of $\mathrm{NO}_{2}$ and $\mathrm{CO}$ during various phases in the district where the subject's residence is located were calculated.

\section{Statistical Analyses}

In descriptive analysis, the demographic characteristics of all participants were shown as mean \pm standard deviation (SD) or percent (\%). Parametric t-tests and $\chi^{2}$ tests were used to compared the difference in demographic characteristics between $\mathrm{SAB}$ cases and healthy controls. $\mathrm{As}_{\mathrm{NO}}$ and $\mathrm{CO}$ exposure levels were not normally distributed, medians (25th -75th percentile) were presented to characterize their distribution in descriptive analysis. Mann-Whitney U-test was used to examine the potential differences in $\mathrm{NO}_{2}$ and $\mathrm{CO}$ exposure between $\mathrm{SAB}$ cases and healthy controls.

Multivariate logistic regression models were used to examine the association between SAB risk and exposure to $\mathrm{NO}_{2}$ and $\mathrm{CO}$ with adjustment for potential confounders. According to the data accessibility and literature studies $[15,19]$, we denoted the following factors to be covariates: GA, MA, body mass index (BMI), maternal parity, the use of ART, temperature and relative humidity. We first conducted single pollutant model with only $\mathrm{NO}_{2}$ or $\mathrm{CO}$ in the multivariate logistic regression models. Then we conducted two-pollutants model to examine the joint effects of $\mathrm{NO}_{2}$ and $\mathrm{CO}$ exposure on $\mathrm{SAB}$. We reported the odd ratio (OR) and $95 \%$ confidence interval $(\mathrm{Cl})$ in association with an interquartile range (IQR) increase in $\mathrm{NO}_{2}$ or $\mathrm{CO}$ concentrations. 
In order to explore the potential dose-response relationships between $\mathrm{NO}_{2}$ exposure and risk of $\mathrm{SAB}$, the distribution of $\mathrm{NO}_{2}$ exposure levels was divided into quartiles and an $\mathrm{OR}$ and $95 \% \mathrm{Cl}$ was calculated for each higher quartile compared with the lowest quartile using multivariate logistic regression analysis. All statistical analysis was performed by using SPSS16.0 software (SPSS Inc., Chicago, IL, USA) and a twosided $p<0.05$ was considered statistically significant.

\section{Result}

\section{Population Characteristics}

Table 1 presents the demographic characteristics of all study participants $(N=2445)$. The average MA of all participants was 33.18 (5.34) years at enrollment. The average GA and BMI was 72.73 (23.29) days and $22.20(3.31) \mathrm{kg} / \mathrm{m}^{2}$, respectively. Of the 2445 participants, 1075 were SAB cases and 1370 were health controls. $S A B$ cases and healthy controls differed with regard to GA, BMI, menstrual cycles, parity and the use of ART. SAB cases and health controls did not differ by MA $(33.15 \pm 4.98$ vs $33.20 \pm 5.60, P=$ 0.819). 
Table 1

Selected characteristics of case and control subjects

\begin{tabular}{|c|c|c|c|c|}
\hline Characteristics $^{\text {a }}$ & $\begin{array}{l}\text { Total } \\
(\mathrm{N}=2445)\end{array}$ & $\begin{array}{l}\text { Case } \\
(\mathrm{N}=1075)\end{array}$ & $\begin{array}{l}\text { Control } \\
(N=1370)\end{array}$ & P-value ${ }^{b}$ \\
\hline Maternal age (years) & $33.18 \pm 5.34$ & $33.15 \pm 4.98$ & $33.20 \pm 5.60$ & 0.819 \\
\hline Gestational age (days) & $72.73 \pm 23.29$ & $78.22 \pm 19.31$ & $68.43 \pm 25.17$ & $<0.001^{\star *}$ \\
\hline BMI $\left(\mathrm{kg} / \mathrm{m}^{2}\right)$ & $22.20 \pm 3.31$ & $22.36 \pm 3.27$ & $22.08 \pm 3.34$ & $<0.001^{\star *}$ \\
\hline \multicolumn{5}{|l|}{ Menstrual cycles } \\
\hline Regular & $2139(87.5 \%)$ & $921(85.7 \%)$ & $1218(88.9 \%)$ & $0.017^{*}$ \\
\hline Irregular & $306(12.5 \%)$ & $154(14.3 \%)$ & $152(11.1 \%)$ & \\
\hline \multicolumn{5}{|l|}{ Parity } \\
\hline Nulliparous & $1005(41.1 \%)$ & $669(62.2 \%)$ & $336(24.5 \%)$ & $<0.001^{\star *}$ \\
\hline Multiparous & $1440(58.9 \%)$ & $406(37.8 \%)$ & $1034(75.5 \%)$ & \\
\hline \multicolumn{5}{|l|}{ ART } \\
\hline Yes & $24(1.0 \%)$ & $24(2.2 \%)$ & $0(0.0 \%)$ & $<0.001^{\star *}$ \\
\hline No & $2421(99.0 \%)$ & $1051(97.8 \%)$ & $1370(100.0 \%)$ & \\
\hline \multicolumn{5}{|c|}{ a Values were shown as mean \pm standard deviation (SD) or percent (\%). } \\
\hline \multicolumn{5}{|c|}{${ }^{\mathrm{b}} \mathrm{p}$ Values were calculated using Student's t-test or $\chi^{2}$-test. } \\
\hline$\star P<0.05, * * P<0.01$ & & & & \\
\hline
\end{tabular}

\section{No And Co Exposure Levels}

Table 2 presents the distribution of $\mathrm{NO}_{2}$ and $\mathrm{CO}$ exposure levels during each specific exposure window (Phases 1-4). The median (25th -75th percentile) $\mathrm{NO}_{2}$ exposure levels for phases 1 - 4 were 41.46 (33.52, 49.52), $40.34(31.85,50.81), 41.00(32.24,50.76)$ and $41.65(32.73,50.11) \mu \mathrm{g} / \mathrm{m}^{3}$, respectively. The median CO exposure levels were $0.68(0.60,0.78), 0.69(0.59,0.80), 0.69(0.60,0.80)$ and $0.69(0.61,0.79)$ $\mathrm{mg} / \mathrm{m}^{3}$, respectively. Exposure levels of $\mathrm{NO}_{2}$ were moderately correlated with $\mathrm{CO}$ during each phase, with the correlation coefficients ranging from 0.633 to 0.680 (Fig. 1). 
Table 2

Exposure Characteristics of $\mathrm{NO}_{2}$ and $\mathrm{CO}$

\begin{tabular}{|c|c|c|c|c|}
\hline Pollutants & $\begin{array}{l}\text { Total }(\mathrm{N}=2445) \\
\left(\mathrm{P}_{50}, \mathrm{P}_{25}-\mathrm{P}_{75}\right)\end{array}$ & $\begin{array}{l}\text { Case }(\mathrm{N}=1075) \\
\left(\mathrm{P}_{50}, \mathrm{P}_{25}-\mathrm{P}_{75}\right)\end{array}$ & $\begin{array}{l}\text { Control }(\mathrm{N}=1370) \\
\left(\mathrm{P}_{50}, \mathrm{P}_{25}-\mathrm{P}_{75}\right)\end{array}$ & P-value ${ }^{a}$ \\
\hline \multicolumn{5}{|c|}{$\mathrm{NO}_{2}\left(\mu \mathrm{g} / \mathrm{m}^{3}\right)$} \\
\hline Phase 1 & $41.46(33.52,49.52)$ & $42.26(34.31,50.12)$ & $40.67(32.74,48.93)$ & $<0.001^{\star *}$ \\
\hline Phase 2 & $40.34(31.85,50.81)$ & $40.00(31.35,51.25)$ & $40.48(32.39,50.42)$ & 0.758 \\
\hline Phase 3 & $41.00(32.24,50.76)$ & $40.40(31.38,51.10)$ & $41.28(32.57,50.42)$ & 0.472 \\
\hline Phase 4 & $41.65(32.73,50.11)$ & $41.55(32.18,50.36)$ & $41.80(33.38,49.81)$ & 0.280 \\
\hline \multicolumn{5}{|c|}{$\mathrm{co}\left(\mathrm{mg} / \mathrm{m}^{3}\right)$} \\
\hline Phase 1 & $0.68(0.60,0.78)$ & $0.69(0.60,0.78)$ & $0.68(0.60,0.78)$ & 0.488 \\
\hline Phase 2 & $0.69(0.59,0.80)$ & $0.69(0.59,0.79)$ & $0.69(0.59,0.80)$ & 0.484 \\
\hline Phase 3 & $0.69(0.60,0.80)$ & $0.69(0.59,0.79)$ & $0.69(0.61,0.80)$ & 0.363 \\
\hline Phase 4 & $0.69(0.61,0.79)$ & $0.69(0.60,0.80)$ & $0.69(0.62,0.79)$ & 0.446 \\
\hline \multicolumn{5}{|c|}{ a $p$ Values were calculated using Mann-Whitney U-test. } \\
\hline \multicolumn{5}{|c|}{$\begin{array}{l}\text { Phase 1: form the last menstrual period to the date of missed abortion, Phase } 2: 30 \text { days before } \\
\text { pregnancy, Phase 3: } 60 \text { days before pregnancy, Phase } 4: 90 \text { days before pregnancy. }\end{array}$} \\
\hline$\star \star P<<0.01$ & & & & \\
\hline
\end{tabular}

Analyses of potential differences in $\mathrm{NO}_{2}$ and $\mathrm{CO}$ exposure levels during each exposure window between $\mathrm{SAB}$ cases and health controls were conducted using the Mann-Whitney U-test. As shown in Table 2, $\mathrm{NO}_{2}$ exposure levels during phase 1 (from the first day of LMP to the date of abortion) were significantly higher in $\mathrm{SAB}$ cases than in healthy controls ( 42.26 vs $40.67, \mathrm{P}<0.01)$. While there was no significant difference in $\mathrm{CO}$ exposure during each exposure window.

\section{Associations Of No And Co Exposure With Sab Risk}

The associations of $\mathrm{NO}_{2}$ and $\mathrm{CO}$ exposure with $\mathrm{SAB}$ risk were investigated. ORs and $95 \% \mathrm{Cls}$ for the risk of $\mathrm{SAB}$ in relation to $\mathrm{NO}_{2}$ or $\mathrm{CO}$ exposure are presented in Table 3. Higher $\mathrm{NO}_{2}$ exposure during phase 1 was significantly associated with increased risk of SAB. In single-pollutant model, an IQR $\left(16 \mu \mathrm{g} / \mathrm{m}^{3}\right)$ increase in $\mathrm{NO}_{2}$ exposure during was associated with $52 \%(\mathrm{OR}=1.52,95 \% \mathrm{Cl}, 1.19-1.95)$ increase in the odds of SAB. A similar result was observed in two-pollutant models with $67 \%(\mathrm{OR}=1.67,95 \% \mathrm{Cl}, 1.28$, 
2.18) increase in the odds of $S A B$ per IQR increase in $\mathrm{NO}_{2}$ exposure during phases 1. However, no significant association was found between $S A B$ risk and $C O$ exposure during any phases.

Table 3

Associations of $\mathrm{NO}_{2}$ and $\mathrm{CO}$ exposure with spontaneous abortion risk

\begin{tabular}{|c|c|c|}
\hline \multirow[t]{2}{*}{ Pollutants } & Single pollutant model ${ }^{a}$ & Two-pollutants models ${ }^{\text {b }}$ \\
\hline & OR (95\% Cl) & OR $(95 \% \mathrm{Cl})$ \\
\hline \multicolumn{3}{|l|}{$\mathrm{NO}_{2}$} \\
\hline Phase 1 & $1.52(1.19,1.95)$ ** & $1.67(1.28,2.18)$ ** \\
\hline Phase 2 & $0.98(0.79,1.22)$ & $0.99(0.77,1.26)$ \\
\hline Phase 3 & $1.00(0.77,1.30)$ & $1.01(0.76,1.35)$ \\
\hline Phase 4 & $0.94(0.71,1.25)$ & $0.96(0.70,1.31)$ \\
\hline \multicolumn{3}{|l|}{$\mathrm{CO}$} \\
\hline Phase 1 & $0.99(0.86,1.14)$ & $0.88(0.76,1.03)$ \\
\hline Phase 2 & $0.99(0.87,1.13)$ & $1.00(0.86,1.15)$ \\
\hline Phase 3 & $0.99(0.86,1.13)$ & $0.98(0.84,1.15)$ \\
\hline Phase 4 & $0.97(0.85,1.11)$ & $0.98(0.85,1.14)$ \\
\hline \multicolumn{3}{|c|}{ a Adjusted for GA, MA, BMI, maternal parity, ART, temperature and relative humidity. } \\
\hline \multicolumn{3}{|c|}{$\begin{array}{l}\text { Phase 1: form the last menstrual period to the date of missed abortion, Phase } 2: 30 \text { days before } \\
\text { pregnancy, Phase 3: } 60 \text { days before pregnancy, Phase 4: } 90 \text { days before pregnancy. }\end{array}$} \\
\hline$\star \star \mathrm{P}<0.01$ & & \\
\hline
\end{tabular}

Given $\mathrm{NO}_{2}$ exposure during phase 1 was found to be significantly associated with increased risk of $\mathrm{SAB}$, we examined the dose-response associations between $\mathrm{NO}_{2}$ exposure during phase 1 and the risk of SAB. As shown in Fig. 2, higher $\mathrm{NO}_{2}$ exposure was associated with increased odds of $\mathrm{SAB}$ in linear doseresponse manners.

In both single-pollutant model, compared with the lowest quartile of $\mathrm{NO}_{2}$ exposure, being in the fourth quartile of $\mathrm{NO}_{2}$ exposure was significantly associated with increased odds of having $\mathrm{SAB}(\mathrm{OR}=1.54,95 \%$ $\mathrm{Cl}, 1.01-2.34)$. Similar results were observed in two-pollutants model. Compared with the lowest quartile of $\mathrm{NO}_{2}$ exposure, the odds of $\mathrm{SAB}$ in the fourth quartile of $\mathrm{NO}_{2}$ exposure increased $60 \%$ (OR $=1.60,95 \%$ $\mathrm{Cl}, 1.03-2.49)$. The trend tests for the above dose-response relationships were statistically significant (single pollutant model, $\mathrm{p}$-trend $=0.053$; Two-pollutants model, $\mathrm{p}$-trend $=0.038$ ). 


\section{Discussion}

$S A B$ is one of the most frequent traumatic life events a woman may encounter. It is associated with various negative psychological outcomes including depression, grief, anxiety and marital conflict [20]. The causes of $S A B$ are likely to be multifactorial $[9,21,22]$. Along with genetic and socioeconomic factors, environmental pollution, including air pollution, may possibly play a role in the development of SAB.

In this study, on the basis of a case-control study design, we investigated the adverse effects of $\mathrm{NO}_{2}$ and $\mathrm{CO}$ exposure on $\mathrm{SAB}$. We found that exposure to $\mathrm{NO}_{2}$ during pregnancy was associated with increased risk of SAB. Moreover, we observed significantly linear dose-response relationships between $\mathrm{NO}_{2}$ exposure and SAB risk. However, we did not find any association between $\mathrm{CO}$ exposure and SAB. Our findings indicate that pregnant women who exposed to higher levels of $\mathrm{NO}_{2}$ during pregnancy might be at higher risk for SAB.

Some studies have investigated the associations between maternal exposure to $\mathrm{NO}_{2}$ and $\mathrm{SAB}$. Most of those reported studies used fixed air monitoring station data to estimate individual $\mathrm{NO}_{2}$ exposure and reported significant positive associations between $\mathrm{NO}_{2}$ exposure and $\mathrm{SAB}$ risk $[18,19,23,24]$. Our findings were consistent with the results of those previous studies. Moreover, one prospective cohort study found that pregnant women living within $50 \mathrm{~m}$ of a road with higher annual average daily traffic was statistically significantly associated with increased risk of SAB [25]. The results of this prospective cohort study also supported our findings since vehicle emissions is a major source of ambient $\mathrm{NO}_{2}$.

For air pollutant of $\mathrm{CO}$, only three studies examined the association of maternal exposure to $\mathrm{CO}$ with the risk of SAB. In agreement with findings from this presented study, both a time-series study and a prospective cohort study did not find any association between SAB risk and CO exposure $[15,26]$. However, a recent study failed to support our findings. Zhang and colleagues examined the records of 255,668 pregnant women from 2009 to 2017 in Beijing, China, and quantified the link between CO exposure and SAB risk. They found long-term exposure to $C O$ before pregnancy was associated with significant increased risk of SAB [17]. Inconsistent results may mainly be ascribed to different study designs and exposure ranges.

The mechanisms of action of $\mathrm{NO}_{2}$ exposure on $\mathrm{SAB}$ are not fully understood. Some studies demonstrated that exposure to $\mathrm{NO}_{2}$ during pregnancy could induce structural or chromosomal anomalies, which are relevant for SAB [27]. Moreover, some previous studies have shown that $\mathrm{NO}_{2}$ exposure could induced oxidative stress and inflammatory responses [28-30], which have been hypothesized to play a role in the development of SAB [31].

Some limitations should be acknowledged. Firstly, we estimated maternal exposure to $\mathrm{NO}_{2}$ and $\mathrm{CO}$ based on fixed-site monitoring station data and ignored the spatial distribution of those two pollutants, which may cause exposure misclassification. Secondly, due to the data inaccessibility, we were unable to collect 
information about some potential risk factors for SAB and thus could not rule out the role of those unmeasured confounders. Thirdly, this is only an exploratory study, we were unable to examine the biological pathways underlying the association between maternal exposure to $\mathrm{NO}_{2}$ and increased risk of SAB.

In summary, our findings suggest that maternal exposure to $\mathrm{NO}_{2}$ during early pregnancy is associated with increased risk of SAB. Further studies are needed to confirm our finding and to explore the biologic mechanisms underlying this association.

\section{Abbreviations}

$\mathrm{NO}_{2}$

Nitrogen Dioxide; SAB:spontaneous abortion; CO:carbon monoxide; GA:gestational age; MA:maternal age; ART:assisted reproduction technology; LMP:last menstrual period

\section{Declarations}

\section{Competing Interests}

The authors have declared that no competinginterest exists.

\section{Consent for publication}

Not applicable

\section{Author Contributions}

Conceptualization: Beiying Wang, Xiaocui Li*

Data curation: Wei Hong, Qingjing Sheng, Zhiping Wu, Li Li,.

Software:Beiying Wang

Supervision: Xiaocui L

Writing \pm original draft: Beiying Wang

Writing \pm review \& editing: Beiying Wang, Xiaocui Li*

\section{Acknowledgements}

No

Funding 
No

\section{Authors' information}

Corresponding author:XiaocuiLi

Department of Obstetrics and Gynecology, Shanghai First Maternity and Infant Hospital, Tongji University School of Medicine, No. 2699, Gaoke Road, Shanghai 201204, P.R. China.

Email address: sisi1113@163.com

First author:Beiying Wang

Department of Obstetrics and Gynecology, Shanghai First Maternity and Infant Hospital, Tongji University School of Medicine, No. 2699, Gaoke Road, Shanghai 201204, P.R. China.

beiyingw@51mch.com

Wei Hong:hw_rock@sina.com

Qingjing Sheng: sqjseu@163.com

ZhipingWu:wzp59@163.com

Li Li: 785348607@qq.com

Department of Obstetrics and Gynecology, Shanghai First Maternity and Infant Hospital, Tongji University School of Medicine, No. 2699, Gaoke Road, Shanghai 201204, P.R. China.

\section{References}

1. Brunekreef B. [Air pollution and health]. Ned Tijdschr Geneeskd 2018, 162.

2. Cohen AJ, Brauer M, Burnett R, Anderson HR, Frostad J, Estep K, Balakrishnan K, Brunekreef B, Dandona L, Dandona R, et al: Estimates and 25-year trends of the global burden of disease attributable to ambient air pollution: an analysis of data from the Global Burden of Diseases Study 2015. Lancet (London, England) 2017, 389(10082):1907-1918.

3. Dominici F, Peng RD, Bell ML, Pham L, McDermott A, Zeger SL, Samet JM. Fine particulate air pollution and hospital admission for cardiovascular and respiratory diseases. JAMA. 2006;295(10):1127-34.

4. Mohammed MO, Song WW, Ma WL, Li WL, Li YF, Khan AU, Ibrahim MA, Maarouf OA, Ahmed AA, Ambuchi JJ. Potential Toxicological and Cardiopulmonary Effects of PM2.5 Exposure and Related Mortality: Findings of Recent Studies Published during 2003-2013. Biomed Environ Sci. 2016;29(1):66-79. 
5. Klepac P, Locatelli I, Korosec S, Kunzli N, Kukec A. Ambient air pollution and pregnancy outcomes: A comprehensive review and identification of environmental public health challenges. Environmental research. 2018;167:144-59.

6. Guo LQ, Chen Y, Mi BB, Dang SN, Zhao DD, Liu R, Wang HL, Yan H. Ambient air pollution and adverse birth outcomes: a systematic review and meta-analysis. J Zhejiang Univ Sci B. 2019;20(3):238-52.

7. Li X, Huang S, Jiao A, Yang X, Yun J, Wang Y, Xue X, Chu Y, Liu F, Liu Y, et al: Association between ambient fine particulate matter and preterm birth or term low birth weight: An updated systematic review and meta-analysis. Environmental pollution (Barking, Essex: 1987) 2017, 227:596-605.

8. Xiong L, Xu Z, Wang H, Liu Z, Xie D, Wang A, Kong F. The association between ambient air pollution and birth defects in four cities in Hunan province, China, from 2014 to 2016. Med (Baltim). 2019;98(4):e14253.

9. Garcia-Enguidanos A, Calle ME, Valero J, Luna S, Dominguez-Rojas V. Risk factors in miscarriage: a review. Eur J Obstet Gynecol Reprod Biol. 2002;102(2):111-9.

10. Rai R, Regan L. Recurrent miscarriage. Lancet. 2006;368(9535):601-11.

11. Grippo A, Zhang J, Chu L, Guo Y, Qiao L, Zhang J, Myneni AA, Mu L. Air pollution exposure during pregnancy and spontaneous abortion and stillbirth. Rev Environ Health. 2018;33(3):247-64.

12. Di Ciaula A, Bilancia M. Relationships between mild PM10 and ozone urban air levels and spontaneous abortion: clues for primary prevention. Int J Environ Health Res. 2015;25(6):640-55.

13. Perin PM, Maluf M, Czeresnia CE, Nicolosi Foltran Januario DA, Nascimento Saldiva PH. Effects of exposure to high levels of particulate air pollution during the follicular phase of the conception cycle on pregnancy outcome in couples undergoing in vitro fertilization and embryo transfer. Fertil Steril. 2010;93(1):301-3.

14. Perin PM, Maluf M, Czeresnia CE, Januario DA, Saldiva PH. Impact of short-term preconceptional exposure to particulate air pollution on treatment outcome in couples undergoing in vitro fertilization and embryo transfer (IVF/ET). J Assist Reprod Genet. 2010;27(7):371-82.

15. Ha S, Sundaram R, Buck Louis GM, Nobles C, Seeni I, Sherman S, Mendola P. Ambient air pollution and the risk of pregnancy loss: a prospective cohort study. Fertil Steril. 2018;109(1):148-53.

16. Hou HY, Wang D, Zou XP, Yang ZH, Li TC, Chen YQ. Does ambient air pollutants increase the risk of fetal loss? A case-control study. Arch Gynecol Obstet. 2014;289(2):285-91.

17. Zhang LQ, Liu WW, Hou K, Lin JT, Zhou C, Tong XH, Wang ZY, Wang YB, Jiang YX, Wang ZW, et al: Air pollution-induced missed abortion risk for pregnancies. Nature Sustainability. 2019, (2):1011-1017.

18. Moridi M, Ziaei S, Kazemnejad A. Exposure to ambient air pollutants and spontaneous abortion. J Obstet Gynaecol Res. 2014;40(3):743-8.

19. Green RS, Malig B, Windham GC, Fenster L, Ostro B, Swan S. Residential exposure to traffic and spontaneous abortion. Environmental health perspectives. 2009;117(12):1939-44.

20. Schwerdtfeger KL, Shreffler KM. Trauma of Pregnancy Loss and Infertility for Mothers and Involuntarily Childless Women in the Contemporary United States. J Loss Trauma. 2009;14(3):211- 
27.

21. Zheng D, Li C, Wu T, Tang K. Factors associated with spontaneous abortion: a cross-sectional study of Chinese populations. Reprod Health. 2017;14(1):33.

22. Zhou H, Liu Y, Liu L, Zhang M, Chen X, Qi Y. Maternal pre-pregnancy risk factors for miscarriage from a prevention perspective: a cohort study in China. Eur J Obstet Gynecol Reprod Biol. 2016;206:5763.

23. Leiser CL, Hanson HA, Sawyer K, Steenblik J, Al-Dulaimi R, Madsen T, Gibbins K, Hotaling JM, Ibrahim YO, VanDerslice JA, et al. Acute effects of air pollutants on spontaneous pregnancy loss: a casecrossover study. Fertil Steril. 2019;111(2):341-7.

24. Enkhmaa D, Warburton N, Javzandulam B, Uyanga J, Khishigsuren Y, Lodoysamba S, Enkhtur S, Warburton D. Seasonal ambient air pollution correlates strongly with spontaneous abortion in Mongolia. BMC Pregnancy Childbirth. 2014;14:146.

25. Kioumourtzoglou MA, Raz R, Wilson A, Fluss R, Nirel R, Broday DM, Yuval, Hacker MR, McElrath TF, Grotto I, et al. Traffic-related Air Pollution Pregnancy Loss Epidemiology. 2019;30(1):4-10.

26. Dastoorpoor M, Idani E, Goudarzi G, Khanjani N. Acute effects of air pollution on spontaneous abortion, premature delivery, and stillbirth in Ahvaz, Iran: a time-series study. Environ Sci Pollut Res Int. 2018;25(6):5447-58.

27. Vrijheid M, Martinez D, Manzanares S, Dadvand P, Schembari A, Rankin J, Nieuwenhuijsen M. Ambient air pollution and risk of congenital anomalies: a systematic review and meta-analysis. Environmental health perspectives. 2011;119(5):598-606.

28. Patel MM, Chillrud SN, Deepti KC, Ross JM, Kinney PL. Traffic-related air pollutants and exhaled markers of airway inflammation and oxidative stress in New York City adolescents. Environmental research. 2013;121:71-8.

29. Lanki T, Hampel R, Tiittanen P, Andrich S, Beelen R, Brunekreef B, Dratva J, De Faire U, Fuks KB, Hoffmann B, et al. Air Pollution from Road Traffic and Systemic Inflammation in Adults: A CrossSectional Analysis in the European ESCAPE Project. Environmental health perspectives. 2015;123(8):785-91.

30. Viehmann A, Hertel S, Fuks K, Eisele L, Moebus S, Mohlenkamp S, Nonnemacher M, Jakobs H, Erbel $\mathrm{R}$, Jockel $\mathrm{KH}$, et al. Long-term residential exposure to urban air pollution, and repeated measures of systemic blood markers of inflammation and coagulation. Occup Environ Med. 2015;72(9):656-63.

31. Gupta S, Agarwal A, Banerjee J, Alvarez JG. The role of oxidative stress in spontaneous abortion and recurrent pregnancy loss: a systematic review. Obstet Gynecol Surv. 2007;62(5):335-47. quiz 353 334.

\section{Figures}



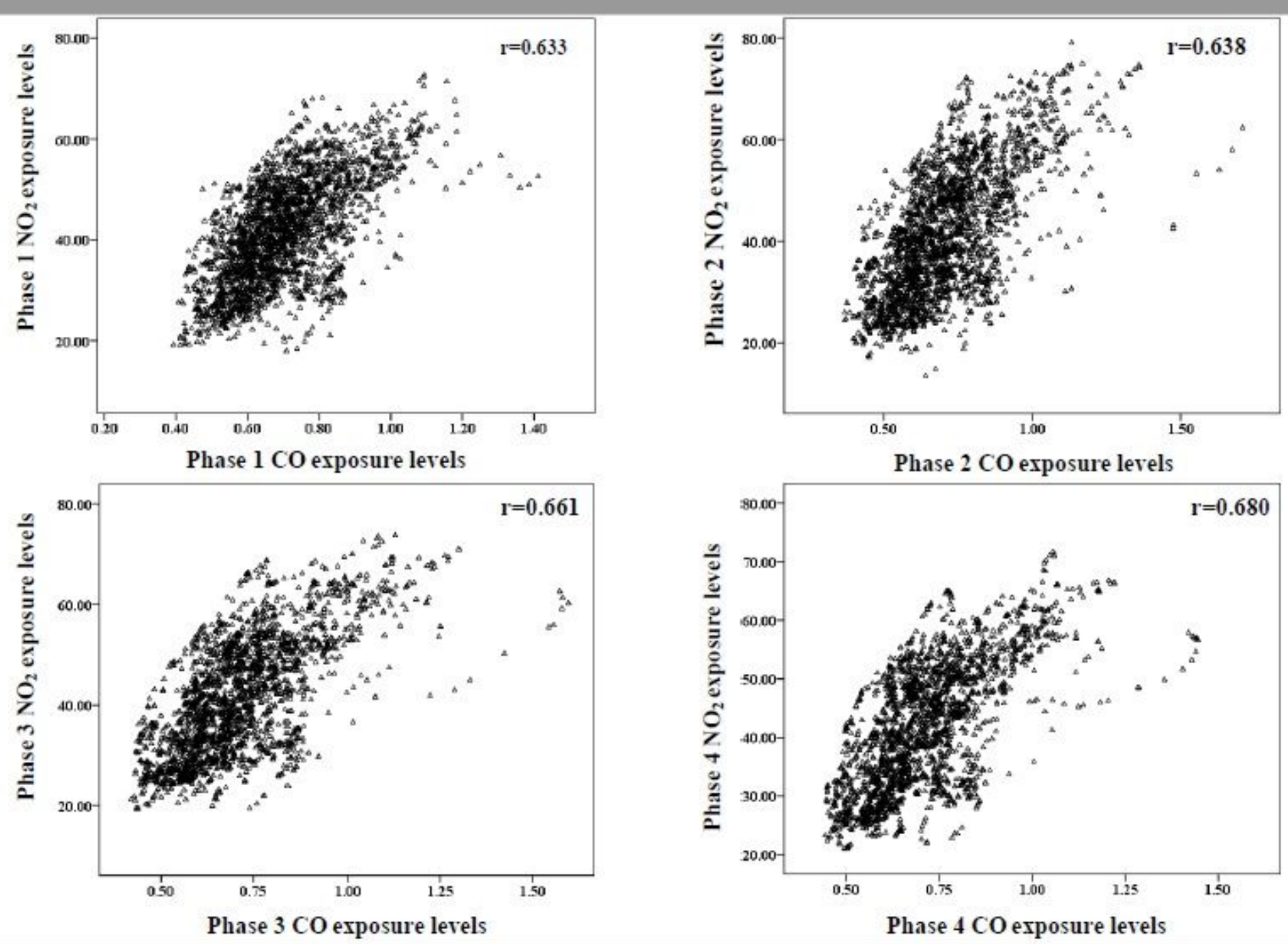

Figure 1

Plots of the correlations between NO2 exposure levels and CO exposure levels. Scatterplots depict the correlation of NO2 exposure levels ( $\mathrm{Y}$ axis) and $\mathrm{CO}$ exposure levels (x axis), with the spearman correlation coefficient ( $r$ ) provided. All spearman correlation coefficients were significant at $p<0.01$. Phase 1 : form the last menstrual period to the date of missed abortion, Phase 2: 30 days before pregnancy, Phase 3: 60 days before pregnancy, Phase 4: 90 days before pregnancy. 


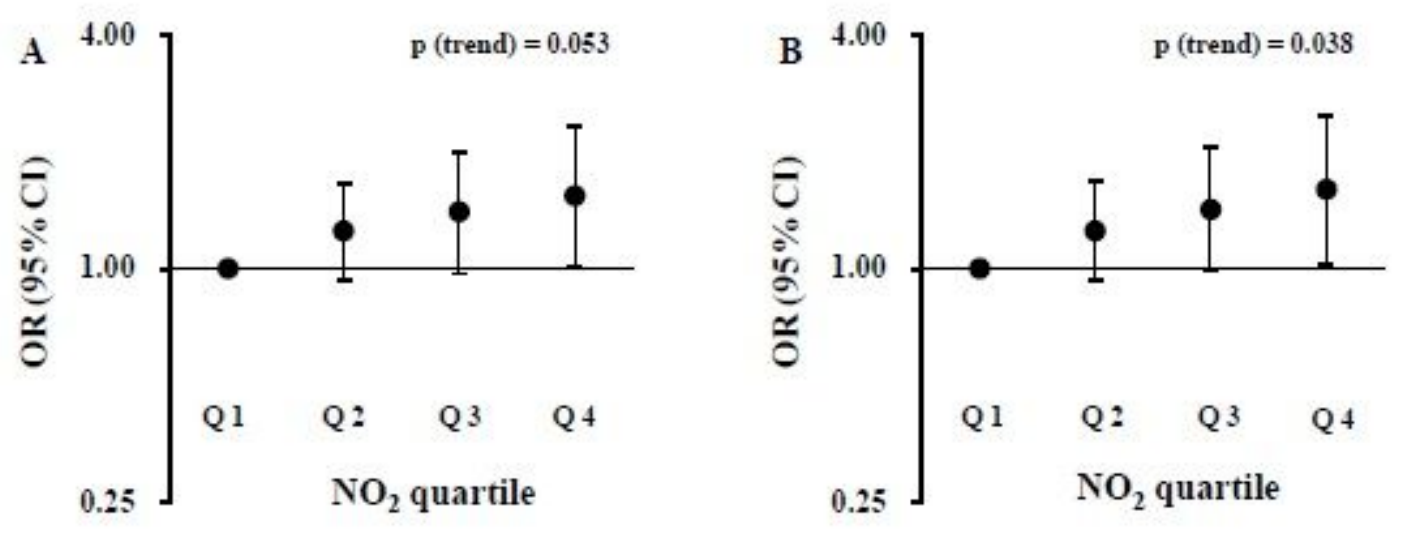

Figure 2

ORs and $95 \% \mathrm{Cl}$ for the associations between NO2 exposure during pregnancy and SAB.(A) Single

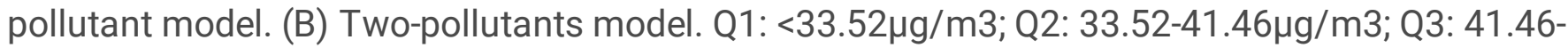
$49.52 \mu \mathrm{g} / \mathrm{m} 3 ; \mathrm{Q} 4:>49.52 \mu \mathrm{g} / \mathrm{m} 3$.First quartile is the reference and models were adjusted for $\mathrm{GA}, \mathrm{MA}, \mathrm{BMI}$, maternal parity, ART, temperature and relative humidity. 